\title{
Digitalisation and enterprise knowledge (net)working
}

\author{
Gergana Vladova \\ University of Potsdam \\ gvladova@1swi.de
}

\author{
André Ullrich \\ University of Potsdam \\ aullrich@1swi.de \\ Benedict Bender \\ University of Potsdam \\ bbender@1swi.de
}

\author{
Julian Bahrs \\ IPI \\ J.Bahrs@ipi-gmbh.com
}

\begin{abstract}
Social media and emerging mobile technologies have forever changed the landscape of human interaction. Furthermore, they already play a pivotal role also in enterprises as a part of the organisational Knowledge Management System. Almost all large organisations have already implemented at least one Enterprise Social Media tool since they enable collaboration, provide easy access to information, and are available at reasonable costs. The effects of the decoupling of the real and the virtual world (as a result of Social Media use) on the construct "knowledge" and on knowledge management are still not sufficiently investigated.

Against this background, the paper presents an exploratory approach of the development of a specific morphological tableau as an instrument for the analysis of employees' behavior in context of knowledge management related ESM use. Furthermore, the application of the tableau is exemplary illustrated and further research steps are explained.
\end{abstract}

\section{Introduction}

Knowledge management systems (KMS) constitute enabling technologies for an effective and efficient knowledge management (KM). During the last decade, there is a trend towards comprehensive and complex KMS and the usage of Enterprise Social Media (ESM), which enable e.g. collaboration, learning, search, communication, knowledge sharing and creation, and social networking [1], [2], [3]. Today, almost all large organizations have already implemented at least an intranet or a groupware platform since they enable collaboration, provide easy access to information, and are available at reasonable costs [4].

Current research shows that socially and workoriented enterprise social network users are closely intertwined [5], whereby not only the passive tool usage, but also context creation and presentation aspects are relevant. Thus, in order to analyze knowledge management related behavior within the ESM context, not only appropriate knowledge management concepts and frameworks but also current results on ESM and Social Media (SM) research in general (such as [4]) should be taken into consideration.

However, the usage of ESM does by far not reach the expectations of the management and the investments carried out in order to implement an ESM. Technological factors do not seem to strongly affect employees' motivation for knowledge sharing, it is more a combination of individual and organizational factors [6]. At the same time, ESM cause positive effect on employees' willingness to share knowledge, whereby knowledge sharing is considered to be more beneficial than knowledge hoarding [6].

In terms of (E)SM, one recent phenomenon is of particular importance: human presentation/identity and behavior differs in real life and in virtual life [7], [8]. Against this background, impression management (online as well as offline) - the creation or the expression of the own identity in a specific way, describing how individuals wish other to perceive them [9] - has become more important. The gap between the two forms of self-objectivation can be described in regard of 1) the stage of as well as 2) the strategy of the identity performance [10], [11] - the offline face-toface communication induces mostly the spontaneous manifestation of the self, whereas the online communication allows a strategic filtering and selection of self-presenting information [12]. The majorities of research papers with focus on selfpresentation and social media adapt Goffman's [13] thesis that individuals aim at controlling the impressions of their environment by manipulating setting, appearance, and behavior. The metaphor considers life as a stage for activity. Individuals, thus, engage in performances [13]. This continued presence allows individuals to tweak their behavior and 
selectively give and give off details, a process he termed "impression management." This thesis has been developed on the basis of the analysis of face-to-face communication, including the reciprocal influence on actions in context of an immediate physical presence, and fitted to the specifics of online communication: social media is an appropriate "stage" on which users create their self-performance [14].

Virtual platforms such as LinkedIn, researchgate, Facebook or even ESM are (mis)used to present an "ideal" version of the person - the digital representation of the self. Therein, users consciously present "polished" context-specific sides of their own personality or, to put it positively, they solely present these qualities, necessary for a specific context. Overestimated presentation of competences, selfrepresentation, looking for recognition, in expression of addiction to "likes" are just a few examples of these effects on the behavior of individuals. Thereof derived, one question regarding the usage of ESM (e.g. collaboration or communication platforms, competence maps, skill management or e-learning tool, discovery or publishing systems) is, how prone they are to this kind of effects.

Given the fact that nowadays knowledge management on individual as well as on organizational level is more and more enabled by ESM, the effects of the decoupling of the real and the virtual world on the construct "knowledge" and on knowledge management are also manifold. Positive results are, e.g., a higher availability and quicker acquisition of knowledge, whereby feedback loops lead to an emergent character of knowledge. On the other hand, also some negative effects of ESM usage within enterprises arise. Deceiving other individuals and wasting the own and others time if the presented knowledge fails to deliver on its promises are just a few possible downsides of the digital representation of the self. Under the assumption that employees experience these downsides and negative effects, the impact on their actions, which constitute real-world manifestations of their knowledge, is indisputable.

Goal of this contribution is to provide a framework for investigating the influence of ESM on knowledge management by considering the individual behavior in the context of different knowledge roles and relevant knowledge activities. To put it more specifically: (1) to deduce and categorize behavior relevant aspects in context of KM and (E)SM research; (2) to exemplarily describe arising behavioral , (3) to build hypotheses in order to show the impact of ESM usage on the management of knowledge in organizations. For this purpose, the applied methods include literature reviews, creativity methods (morphological tableau) as well as exemplary conducted scenarios.
[1] point out three main complexity sources of comprehensive KMS: 1) technical complexity and large data volumes; 2) organizational complexity caused by the affection of both, business as well as KM processes; 3) human complexity due to the integration of KMS into daily practices of knowledge work and the substantial changes in habits, roles, tasks and responsibilities. They correspondent to the three main dimensions of KM in organizational context: people, technology and organization [15]. Against this background, these three dimension as well as the application of knowledge and knowledge management theories build the underlying conceptual knowledge management framework of the research within this paper.

The remainder is structured as follows. Section 2 introduces the specifics of enterprise knowledge networking, addresses aspects such as knowledge and knowledge management as well as ESM in knowledge work. Section 3 focuses on the relevant socio-technical elements: individual, organization, and technology. Section 4 introduces the developed morphological tableau, which is further more exemplarily described on behalf of diverse scenarios in section 5. Section 6 discusses, summarizes, and closes with an outlook.

\section{Enterprise knowledge (net)working}

According to [16] and [17], there are two dominant approaches regarding $\mathrm{KM}$ initiatives in organizations: codification (with emphases on the usage of technology and on explicit knowledge) and personalization (focus lies on tacit knowledge and therefore on people and cultural issues), whereby KMS can be used in order to support both strategies or an integrated one. Thus, following two relevant aspects have been pointed out within the context of this work: the specifics of knowledge as a resource within an enterprise as well as the role of ESM in context of KM.

\subsection{Knowledge types and the management of knowledge}

KMS and ESM in particular address both, 1) dealing with information and data as well as 2) the connection and communication between employees. These two views correspond with the two main categories in knowledge and knowledge management theory: explicit knowledge - which is equivalent to 1) and can be distributed in a formal and systematic language - and creating environments to share tacit knowledge - which is ,personal, context specific and very difficult to communicate" and corresponds with 2) [18]. According to the epistemological doctrine, 
knowledge can be described in the context of a clear separation between a subject and an object. Tacit knowledge as a new dimension has been introduced by [19] in order to describe knowledge not only as a part of the independently existing reality, but also as part of the individual mental models that represent already collected individual knowledge. The handling of the two knowledge types requires the application of diverse methods and approaches in consideration of their features. Besides the above described, two other knowledge types are of particular importance in context of enterprise KM: 3) Individual knowledge that is "possessed" by a single entity and 4) collective knowledge possessed by a team or the organization as a whole, as well their goal-oriented transfer and interplay [20].

Knowledge management aims to positively influence business value generated from knowledge by addressing the described knowledge types (e.g. [18], [21]. This is achieved by creating an environment of processes, culture and technology in which knowledge sharing is regarded positively and performed frequently.

The relevant knowledge types build one respective dimension within the developed analysis framework (s. Fig. 2).

\subsection{ESM in the context of knowledge work}

With regard to the previous described specifics of knowledge, its management remains - despite of the technological development - personal. Managing tacit knowledge means managing individuals. Additionally, given the dynamic nature of knowledge, the handling of explicit knowledge (data and information) is also closely linked to the management of the human factor.

Hereby, Social Media opens up new perspectives, introduces new possibilities to "externalize, share, create knowledge and innovate through co-creation processes, crowdsourcing or synergetic articulation of personal into collective knowledge" [22]. However, in order to be successful, ESM has to achieve a critical mass of users, whereby particularly human interaction remains to be most important (ibid.).

Given the advantages of the implementation of ESM and the fact that individuals and organizations become more connected and more social, there are some challenges to cope with [22]:

KM should use SM tools in order to become more personal and target user needs. Additionally, KMS should be configured and designed for the special practices of individual knowledge workers, enabling them to engage in more interactions and enhancing task performance. Furthermore, knowledge workers need to understand and experience the benefits of participation and online interaction through ESM.

The usage of social media enables the management of individual and collective knowledge with a varying degree of interaction and control. However, given the specific of the social media age, the self-management as well as the management of the personal knowledge are as important as the management of collaborations or the management of the collective or organizational knowledge.

[22] explain in the context of ESM-usage the individual motivation as, driven by personal motives and expected personal benefits (e.g. monetary value, increased intangible capital, such as reputation, social capital, self-accomplishment). Apart from the human factor, the usage of ESM is also influenced by two more factors: the organizational culture and leadership support as well as the technology itself, especially its relevancy, usefulness, and easy operation [22].

\section{Socio-technical aspects}

In order to investigate the handling of tacit and explicit knowledge via ESM, three main elements of the socio-technical system have been addressed within this paper: 1) the individual (knowledge bearer); 2) the organizational framework (the rules and shapes of the social constructed reality); 3) the enablers (e.g. the functions of the ESM). These three elements are crucial in research work on both, KM as well as (E)SM use. In the following, they will be described in detail and with regard to this paper.

\subsection{The individual}

Individuals' actions, decisions and behavior strongly depend on the situational interaction context (cf. [23]). Within enterprises, the usage of ESM allows the direct, specific and continuous involvement of individuals in different social and work-related communication and collaboration situations, without time or geographical restrictions, and even without the restriction of knowing each other in person. In other words - the number and the complexity of possible interaction contexts grow.

On the one side, this behavior is influenced by aspects that are more heterogeneous than 1) in a usual face-to-face situation (e.g. given the fact that the audience is much wider and possibly anonymous and the messages are more sustainably available) as well as than 2) when using a tool that aims only at the data/information transfer, such as E-Mail.

On the other side, the role of the individual within the communication process is influenced by the 
organizational context and by the individual's own position within the KM system.

Thus, individual behavior should be analyzed from two perspectives: the social one (in consideration with social-psychology theories) as well as the knowledge management one (in consideration with knowledge management tasks).

Regarding the first perspective, the research on ESM as well as the development of appropriate theoretical concepts can benefit from the much longer research history on Social Media in general, including profile analysis (profiles are analyzed as an user's individual possibility to personalize the own representation on social media platforms [24], [25]); activity aspects such as group memberships and active commenting [25] as well as motivation of use and the actual use of social media platforms, e.g. maintaining long-distance relationships, game playing, entertainment, photo-related activities, organization of social events as well as establishing new friendships [12].

Furthermore, psychological aspects of context creation and presentation have been well researched. Social-psychology theories can be used in order to explain individual and collective motives, user behavior and participation in KM-activities. Following motives for ESM-use can be pointed out from this research context:

- engagement in KM-activities because these are seen as important or interesting (selfdetermination theory).

- participation due to an expected tangible benefit such as visibility or reputation (social exchange theory or social dilemma theory).

- contribution to certain individual needs such as desire for self-accomplishment (selfefficacy theory).

- the desire to belong to a group and to help others (altruism).

[22] summarize, that direct outputs of actions as a response of these motives will be very beneficial for enterprise knowledge management.

In order to systemize the social aspects, the parameter dimension "social motives" has been developed (s. Fig. 2)

However, in organizational context, individuals are in the first place employees, whereby the technology is given as a tool in order to fulfill their work-related tasks. Thus, the second perspective should also be taken into consideration.

[26] identify three relevant role within the KM framework in enterprises: knowledge workers, knowledge managers and managers.

Knowledge workers are highly educated and experienced employees whose main asset is their knowledge and due to this, they are able to retain considerable autonomy and discretion in conducting their work [27], [28]. The "purpose of their jobs involves the creation, distribution, or application of knowledge" [29]. Colloquially speaking, their job is to "think for a living". Typical examples are, amongst others, academics, consultants, engineers, lawyers, scientists, or software engineers.

Knowledge managers are professionals, directly assigned to develop and monitor knowledge management strategies in enterprises. Their functions include management functions, communications, human resources and networkin [30].

Managers, on the other side, are responsible for the general strategy of the enterprise as well as for the definition of its goals. Their decisions influence the corporate culture, the technological structure as well as the operative process flows.

The parameter dimension role and the attributes knowledge worker, knowledge manager and manger for separation of possible roles has been developed against this theoretical background (s. Fig. 2).

\subsection{The organizational framework}

The organization as a socialization context is the defining instance for individual behavior when acting as its member [23], [31]. This includes background themes such as culture (norms and values) as well as operational aspects such as processes and tasks.

Knowledge management tasks - that build a particular focus within this paper - can be considered as ancillary tasks or interventions in the organization. They have planning, controlling, and measuring character and are realized by different measures. Therein, the selection, adaptation and introduction of measures already pose a part of a task. The measures influence the design areas of knowledge management in an individual manner. 


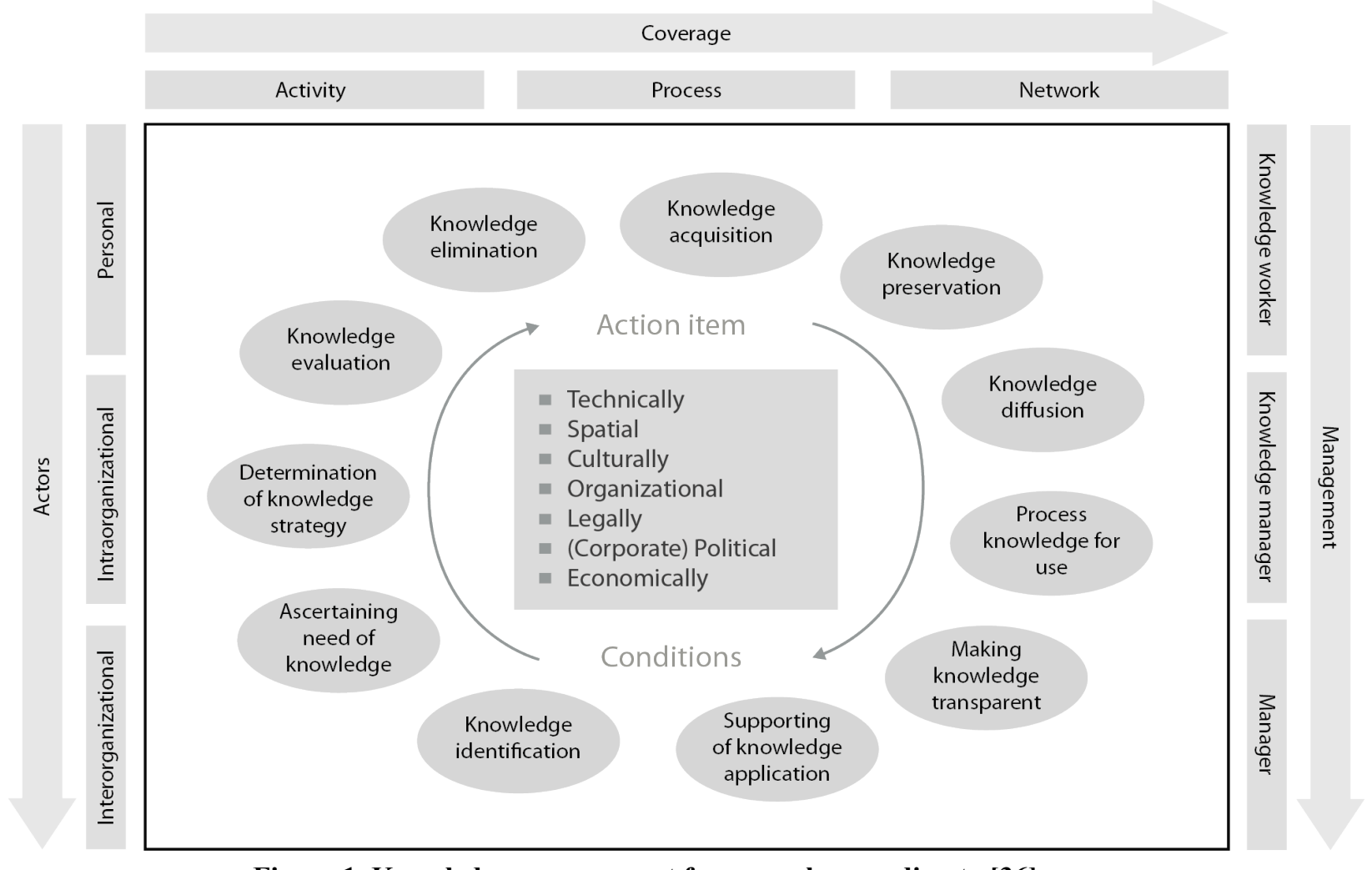

Figure 1. Knowledge management framework according to [36].

Following previous research (such as [21], [32], [33], [34], [35], [18]), [36] developed a knowledge management framework (Fig 1) that comprises eleven knowledge management tasks. 1) Determination of knowledge strategy: the knowledge strategy describes the importance of knowledge in an organization, the measures for the preservation and extension of available knowledge as well as the extend of the respective financial, organizational, and technical effort. 2) Ascertaining knowledge needs: goal is the determination of operatively necessary explicit and tacit knowledge on an individual level. 3) Knowledge identification: comprises recognition and description of internal and external knowledge in a value creating process. 4) Making knowledge transparent: This task represents the identified internal and external knowledge sources of an organization and makes them properly available to employees and if necessary customers, suppliers etc. 5) Prepare knowledge for usage: This task comprises the transformation of knowledge into a kind that it is better and faster usable for current and future tasks. 6) Knowledge preservation: provide employee as well as organizational knowledge systematically for coping with business processes. 7) Knowledge diffusion: topdown steering of the diffusion as well as the selforganised distribution by employees (bottom-up) with the goal of bringing the knowledge to the place of need. 8) Knowledge elimination: This task comprises renewal, replacement, or deletion of organizational knowledge. 9) Supporting knowledge application: deployment of respective structures, processes, and systems for increasing the degree of knowledge usage on the individual level. 10) Knowledge evaluation: process- and organization-relevant evaluation of knowledge within the organization. 11) Knowledge acquisition: knowledge will either be externally acquired from consultants, experts, or documents or internally build up via qualification measures, case studies etc.

The described knowledge task build the respective analysis parameter dimension within the developed framework (s. Fig. 2).

\subsection{The technical enablers}

Given the complexity and variety of knowledge management relevant aspects in enterprises on the one hand, as well as the huge amount of data and information on the other hand, information systems are often needed and implemented in order to support organizational knowledge management. Generally speaking, such kinds of platforms are usually referred to as knowledge management systems - an information and communication system that combines and integrates functions for the structured and 
contextualized handling of organizational explicit and tacit knowledge [36], [37]. Their basic functions include content management, information retrieval, visualization and aggregation of knowledge, and collaboration. Since nowadays collaboration is often characterized by distributed work without any timely limits and cloud computing facilitates, inter alia, scalability, cost-efficiency, availability, and location independence, there exist also a tendency towards cloud-based KMS. As a result of the ICT and web technologies evolution, knowledge management becomes "less costly, more cloud-based, ubiquitous, standardized, and mobile, but also more personalized and more effective in meeting individual needs" [38].

[22] see the impacts of social media integration within the $\mathrm{KM}$ processes in regard to the support of more effectively business communication, social networking and "strategic self-presentation" [39]. According to [29] and [40] the implementation of social media platforms within enterprises has the potential of overcoming knowledge management problems like information overload, productivity diminishment, missing practical benefits, or missing possibilities to capture knowledge. Enterprise social media platforms however, "focus not on capturing knowledge itself, but rather on the practices and output of knowledge workers" [40], being on the other hand also subject to network effects.

ESM are "web-based platforms that allow to (1) communicate messages with specific coworkers or broadcast messages to everyone in the organization; (2) explicitly indicate or implicitly reveal particular coworkers as communication partners; (3) post, edit, and sort text and files linked to themselves or others; and (4) view the messages, connections, and text communicated, posted, edited and sorted by anyone else in the organization at any time of their choosing" [39]. While other knowledge management systems also include the first three aspects of this definition, the fourth aspect is unique to ESM [39] and embodies its openness. ESM can be perceived as a knowledge management system that makes knowledge sharing and communication transparent for others [39]

Within the enterprise, ESM afford the possibility of making visible formal as well as - if necessary informal communication activities in which employees engage at work (e.g. information transfer, networks, outputs of their work). The most important aspect of the visibility and persistence of the communication in ESM is that they enable employees to learn from the communication of others. Thus, simply by participating in ESM, metaknowledge (knowledge about knowledge sources and knowledge carriers), procedural, causal, relational as well as instrumental knowledge can be transferred. On the other hand, ESM can be also used outside the enterprise - in order to connect, collaborate, communicate and create value to external partners, such as business partners or customers. This could be described by the term social business, which is, according to [41], "an organization that strategically engages, analyses and manages social media to structure organizational processes and to support organizational functions in order to realize operational efficiencies, generate comparative advantages, and create value for customers, shareholders, and other societal stakeholders". By this means, knowledge is made visible not only for internal but also for external, as well as not only for known but also for unknown recipients.

The ESM functions build one additional dimension within the morphological tableau (s. Fig. 2).

\section{Morphological tableau of ESM relevant aspects in $\mathrm{KM}$ context}

Against the presented theoretical background and challenges, the question arises of how to structure future theoretical as well as applied research on knowledge management related ESM use. As shown above, user behavior depends on different aspects: the specific individual role within the knowledge

\begin{tabular}{|c|c|c|c|c|c|c|c|c|c|c|c|}
\hline Roles & $\begin{array}{l}\text { knowledge } \\
\text { worker }\end{array}$ & $\begin{array}{l}\text { knowledge } \\
\text { manager }\end{array}$ & manager & $\begin{array}{l}\text { external } \\
\text { society }\end{array}$ & & & & & & & \\
\hline $\begin{array}{l}\text { ESM } \\
\text { functions }\end{array}$ & $\begin{array}{l}\text { communi- } \\
\text { cation / } \\
\text { collaboration }\end{array}$ & $\begin{array}{l}\text { self- } \\
\text { presentation } \\
\text { and person } \\
\text { identification }\end{array}$ & $\begin{array}{l}\text { data and } \\
\text { information } \\
\text { transfer }\end{array}$ & $\begin{array}{l}\text { monitoring } \\
\text { of } \\
\text { activities }\end{array}$ & $\begin{array}{l}\text { access to } \\
\text { shared } \\
\text { data and } \\
\text { information }\end{array}$ & & & & & & \\
\hline $\begin{array}{l}\text { Knowledge } \\
\text { tasks }\end{array}$ & $\begin{array}{l}\text { Determination } \\
\text { of knowledge } \\
\text { strategy }\end{array}$ & $\begin{array}{l}\text { Ascertaining } \\
\text { knowledge } \\
\text { needs }\end{array}$ & $\begin{array}{l}\text { Knowledge } \\
\text { identification }\end{array}$ & $\begin{array}{l}\text { Making } \\
\text { knowledge } \\
\text { transparent }\end{array}$ & $\begin{array}{l}\text { Prepare } \\
\text { knowledge } \\
\text { for usage }\end{array}$ & $\begin{array}{l}\text { Knowledge } \\
\text { preservation }\end{array}$ & $\begin{array}{l}\text { Knowledge } \\
\text { diffusion }\end{array}$ & $\begin{array}{l}\text { Knowledge } \\
\text { elimination }\end{array}$ & $\begin{array}{l}\text { Supporting } \\
\text { knowledge } \\
\text { application }\end{array}$ & $\begin{array}{l}\text { Knowledge } \\
\text { evaluation }\end{array}$ & $\begin{array}{l}\text { Knowledge } \\
\text { acquisition }\end{array}$ \\
\hline $\begin{array}{l}\text { Social } \\
\text { motives }\end{array}$ & $\begin{array}{l}\text { important or } \\
\text { interesting }\end{array}$ & $\begin{array}{l}\text { expected } \\
\text { tangible } \\
\text { benefit }\end{array}$ & $\begin{array}{l}\text { individual } \\
\text { needs }\end{array}$ & $\begin{array}{l}\text { self- } \\
\text { accomplish } \\
\text { ment }\end{array}$ & $\begin{array}{l}\text { belong to a } \\
\text { group and } \\
\text { help others }\end{array}$ & & & & & & \\
\hline $\begin{array}{l}\text { Knowledge } \\
\text { types }\end{array}$ & tacit & explicit & collective & individual & & & & & & & \\
\hline
\end{tabular}

Figure 2. Morphological tableau. 
management system, the knowledge management tasks defined by the organization (specific culture, processes, goals) and relevant for the user as a staff member, the individual social motives according to the socio-psychology theories, as well as the types of knowledge. Furthermore, the specific technical features as well as the limitations of the ESM build one more behavior relevant aspect, since they establish and determine the communication context.

For gaining an overview of conceivable and possible combinations of the presented relevant aspects, the morphological tableau - an instrument of the systematic creativity management that is suitable for the construction of typologies [42] - is utilized. In the first column, the matrix contains the relevant parameter of an investigation object. The respective rows represent a systematization of possible relevant and permitted characteristics of each of these parameters. Accordingly, a finite amount of parameters leads to a finite amount of possible parameter characteristic combinations, which can be used - as in the present case - for the definition of behavior determining contexts.

Considering the variety of influence that one or the combination of more than one of these factors may exert, the goal of this contribution lies in the development of a specific morphological tableau as an appropriate instrument for the analysis of employees' behavior in context of knowledge management related ESM use. The added value consists in the strong alignment with the variety of role-contextcombinations, in their categorical systematization, including the detailed listing of their characteristics. Using the developed morphological tableau, different combinations of roles, functions, tasks, knowledge types and social motives can be analyzed, in order to investigate and describe ESM-users behavior in KMcontext. The particular challenge lies in the big majority of possible aspects combinations.

\section{Exemplary illustration and hypotheses development}

The introduced morphologic tableau allows for isolated reviewing of cases and formulating of hypotheses, which is an object of our future investigations. In the following four selected possible combinations and hypothesis outlines will be discussed.

Example $\boldsymbol{A}$ : Role: knowledge worker; ESM function: person identification (search); knowledge task: knowledge identification; social motive: important or interesting; knowledge type: tacit knowledge
In case that an ESM, such as Yammer, Slack, Workplace by Facebook, Confluence or Stackfield, has been introduced and maintained, the identification of tacit knowledge becomes possible based on full text search possibilities in previous conversations. The (possibly) available content of searching activities with keywords or hashtags could deliver two types of results: 1) artefacts of previously externalized knowledge and, 2), indications of possible knowledge bearers, identified on the basis of their profile information or of their previous online activities, such as conversations or postings of a knowledge bearer, within the ESM. In consideration with aspects like organisational acceptance and positive result expectation, knowledge workers are expected to become more motivated to actually use the platform and, as a consequence, to discover or identify knowledge. Possible obstacles are within the missing acceptance, resulting in not using the platform and thus in a lack of content, the inability to identify relevant knowledge domains in matching search requests (e.g. language barriers), the lack of conversation by reason of the topic or caused by limited access rights. Thus, relevant results could remain unidentifiable for the knowledge worker. Alternative combinations show similar analysis results regarding the roles of knowledge manager or manager.

As a result of this analysis, following hypothesis is postulated: Companies with ESM are more able to identify existing tacit knowledge.

Example B: Role: knowledge worker; ESM function: self-presentation and person identification; knowledge task: knowledge preservation; social motive: belonging to a group; knowledge type: tacit knowledge.

For ESM it is usual to enable the digital representation of employees and their metadata, such as contact information, location, job title as well as descriptions of knowledge domains in which an employee is interested or has experience. Profile descriptions are self-maintained, include endorsements from others, e.g. colleagues, or are a part of an official organisational process, e.g. are approved by the Human Resources department. Especially the self-description is prone to misuse due to the overly idealistic selfpresentation. Typical motives are the motivation to meet the expectations of others or intended career ambitions. As a consequence, the company gets the impression that certain knowledge areas are sufficiently represented by appropriate experts. However, these results are only falsely positive.

The actuality of users profiles is another critical issue. However, a digital representation of the user is a first step towards making this information and knowledge visible for others and motivates through 
possible feedback and peer pressure to maintain profiles. Therefore, another hypothesis reads: Companies with ESM do not have better knowledge, they are just overly positive represented.

Example $\boldsymbol{C}$ : Role: manager; ESM function: collaboration; knowledge task: defining knowledge strategy; social motive: important or interesting, knowledge type: collective knowledge

Defining a knowledge strategy is crucial for the development of new domains expertise. The activities within this task rely on a prior identification of knowledge and its matching with future required knowledge. In general, this process can be characterized as a weak one due to the fact, that future needs can be captured only with assumptions and predictions. Managers however can create a ESMdiscussion group of employees as well as e.g. knowledge managers, and discuss, vote or approve scenarios or possible influences. The definition of a knowledge strategy, therefore, involves more perspectives and may be easier to accomplish than during scheduled meetings with globally distributed experts. Accordingly, another hypothesis is stated: Companies with ESM involve more experts in defining a knowledge strategy and thus define more appropriate knowledge strategies.

Example D: Role: knowledge worker; ESM function: search (access to shared data or information); Knowledge task: knowledge acquisition; social motive: important or interesting; knowledge type: collective knowledge.

The searching for explicit or tacit (identification of knowledge bearers) knowledge has already been discussed (see example A). Beside of the results of this discussion, this searching could further have also effects on knowledge acquisition. Given the limitations of a single searching activity, it appears to be much easier to access knowledge using recommendation rendered by artificial intelligence or by questioning other employees. Knowledge workers spend a lot of time in order to stay informed or to help others. This reduces positive effects, e.g. of reuse of previous experience or work. Thus, the efforts for providing knowledge and information and for their acquisition should be in a positive balance. Therefore, the following hypothesis is stated: Companies with ESM have a better balance between their focused efforts in knowledge creation and distribution on the one hand and knowledge use o the other hand.

\section{Discussion and Outlook}

Knowledge economics is a field of rising interest in the area of knowledge management that deals with the financial impact of knowledge creation, modification, distribution and usage [43]. Especially, the financial aspects of the identification, acquisition, creation, preservation, or distribution of knowledge are nonnegligible [44]. The economical consideration of knowledge management especially applies to the implementation of knowledge management systems (KMS) and collaboration systems as well as the resulting enterprise social networks (ESN). An efficient handling of employees, their knowledge and their competencies leads to potential financial benefits [45] on the basis of increasing the efficiency, effectiveness, or value of processes, services, or products. This in turn has an impact on the economic perspective of an enterprise, such as the ability to innovate faster, to learn and adapt faster to changes.

On basis of the discussion of the four exemplarily used parameter combinations, supporting arguments for positive effects of ESM on knowledge work as well as for self-reflexion regarding knowledge activities have been exemplary illustrated.

Given the fact that the implementation of an ESM is bound to significant investments, investment returns are given only, if the technology is accepted and used. The construction of possible combinations based on the morphological tableau as well as their analysis can be used in enterprise context in order to better understand the behavior of ESM users in context of KM. As a next step however, further parameter combinations will be constructed, the hypothesis will be improved and one first empirical validation via qualitative interviews will be conducted.

\section{References}

[1] R. Maier and D. Hädrich (2005), „Knowledge Management Systems“. In: Schwartz, D. Encyclopedia of Knowledge Management. Idea Group References, p. 442-450

[2] N. Ellison, J., Gibbs and M. Weber (2015), „The use of enterprise social network sites for knowledge sharing in distributed organizations: the role of organizational affordances". American Behavioral Scientist, 29(1), 103123.

[3] M. Koch, A. Richter and A. Schlosser (2007), „Produkte zum IT-gestützten Social Networking im unternehmen“. In Wrtschaftsinformatik 49 (2007) 6, p. 448-455 (in German)

[4] J. Bughin and M. Chui (2007), „Evolution of the networked enterprise: McKinsey Global Survey results“. http://www.mckinsey.com/business-functions/digital- 
mckinsey/our-insights/evolution-of-the-networkedenterprise-mckinsey-global-survey-results

[5] M. Mäntymäki and K. Rieme (2016), „Enterprise social networking: A knowledge management perspective.“ International Journal of Information Management. Volume 36, Issue 6, Part A, December 2016, p. 1042-1052

[6] P. Nielsen and L. Razmerita (2014), Motivation and Knowledge Sharing through Social Media within Danish Organizations. In: Bergvall-Kåreborn B., Nielsen P.A. (eds) Creating Value for All Through IT. TDIT 2014. IFIP Advances in Information and Communication Technology, vol 429. Springer, Berlin, Heidelberg

[7] J. T. Hancock (2007), Digital deception: When, where and how people lie online. In K. McKenna, T. Postmes, U. Reips, \& A. N. Joinson (Eds.), Oxford handbook of internet psychology (pp. 287-301). Oxford, UK: Oxford University Press.

[8] J.K.-H. Chiang and H.-Y. Suen (2015), Self-presentation and hiring recommendations in online communities: Lessons from LinkedIn. Computers in Human Behavior, 48 (2015) 516-524.

[9] Rosenberg, J., and Egbert, N. (2011), Online impression management: personality traits and concerns for secondary goals as predictors of self-presentation tactics on Facebook. Journal of Computer-Mediated Communication, 17 (2011), $1-18$.

[10] Hewitt, A., and Forte, A. (2006), Crossing boundaries: Identity management and student/faculty relationships on the Facebook, Poster presented at: $C S C W$, Banff, Alberta, pp. 12.

[11] Zhao, S., Grasmuck, S., and Martin, J. (2008), Identity construction on Facebook: Digital empowerment in anchored relationships," Computers in Human Behavior, 24 (2008), 1816-1836.

[12] L. P. Tosun (2012). "Motives for Facebook Use and Expressing "True Self" on the Internet," Computers in Human Behavior (28:4), pp. 1510-1517.

[13] E. Goffman (1959) "The presentation of self in everyday life,” New York, NY: Anchor Books.

[14] B. Hogan (2010). "The presentation of self in the age of social media: Distinguishing performances and

exhibitions online," Bulletin of Science, Technology \& Society, (30:6), pp. 377-386.

[15] H.-J. Bullinger, K. Wörner and J. Prieto (1998). Wissensmanagement - Modelle und Strategien für die Praxis, in: B.H.D., Wissensmanagement - Schritte zum intelligenten Unternehmen, p. 21-39.

[16] E. Tsui (2003). „Tracking the Role and Evolution of Commercial Knowledge Management Software.“ In
Holsapple, C. W. (Ed.), Handbook on Knowledge Management 2: Knowledge Directions, Berlin, Springer.

[17] M. Hansen, N. Nohria and T. Tierney (1999), "What's Your Strategy for Managing Knowledge," Harvard Business Review, 77 (2), 106-114.

[18] I. Nonaka and H. Takeuchi H. (1995), The knowledgecreating company - how japanes companies create the dynamics of innovation. New York: Oxford University Press.

[19] M. Polanyi (1967). The tacit dimension. Garden City, N.Y.: Anchor Books.

[20] I. Nonaka (1994) "A Dynamic Theory of Organizational Knowledge Creation". Organization Science ( 5:1), pp. 1437.

[21] G. Probst, S. Raub, and K. Romhardt (2005). Wissen managen. Wie Unternehmen Ihre wertvollste Ressource nutzen. Bd. 5 Gabler (in German)

[22] L. Razmerita, G. Phillips-Wren and L. Jain, L. C. (2015). Innovations in Knowledge Management. The Impact of Social Media, Semantic Web and Cloud Computing. Springer Verlag Berlin Heidelberg

[23] P. L. Berger and T. Luckmann (1966), The Social Construction of Reality: A Treatise in the Sociology of Knowledge, Garden City, NY: Anchor Books.

[24] N. J. Hum, P.E. Chamberlin, B. L. Hambright, A.C. Portwood, A. C. Schat, and J.L. Bevan (2011). "A Picture Is Worth a Thousand Words: A Content Analysis of Facebook Profile Photographs," Computers in Human Behavior (27:5), pp. 1828-1833.

[25] A. Siibak (2009). "Constructing the Self through the Photo Selection-Visual Impression Management on Social Networking Websites," Cyberpsychology: Journal of psychosocial research on cyberspace (3:1).

[26] N. Gronau, A. Ullrich, E. Weber, C. Thim (2012), Creativity Techniques as Operative Knowledge Management Tools - A Case Study. In: Proceedings of the 13th European Conference on Knowledge Management. pp. 425-432. Academic Conferences Limited. Univisidad Politcnica de Cartagena, 6-7 September 2012, Spain

[27] J. Kowal and A. Jasińska-Biliczak (2016), "SocioDemographic Factors of Innovative Capacity of IT Professionals in Small Regional Enterprises in Transition Economies," European, Mediterranean \& Middle Eastern Conference on Information Systems 2016 (EMCIS2016), June 23th -24 th 2016, Krakow, Poland

[28] J. Kowal (2017). Gender and Business Competences of Knowledge Workers in Poland. In Proceedings of the 50th Hawaii International Conference on System Sciences. 
[29] Th. D. Davenport (2005). Thinking for a Living. How to Get Better Performance and Results from Knowledge Workers. Harvard Business School Press

[30] A. Asllani and F. Luthas (2003). What knowledge managers really do: An empirical and comparative analysis. Journal of Knowledge Management, 7(3):53-66

[31] P. Thornton, P. and W. Ocasio (2008). Institutional logics. In K. Sahlin--Andersson, R. Greenwood, C. Oliver, \& R. Suddaby (Eds.), The SAGE handbook of organizational institutionalism (Vol. 105, pp. 99-129). London.

[32] K. Mertins, P. Heisig, J. Vorbeck (2003): Business Process oriented Knowledge Management. In: K. Mertins, P. Heisig, J. Vorbeck: Knowledge Management - Concepts and Best Practices. Berlin: Springer, p. 15-44.

[33] APQC, Consulting, anderson (2000): Succesfully implementing Knowledge Management. Forschungsbericht, (in German).

[34] R. Capurro (1998): Wissensmanagement in Theorie und Praxis. In: Bibliothek: Forschung und Praxis Bd 22. 1998, p. 346-355 (in German)

[35] C. O'Dell and J.C. Grayson (1988): If only we knew what we know: The transfer of internal knowledge and best practice. Free Press.

[36] N. Gronau, N. (2009). Process-oriented Knowledge Management: Methods and Tools for Utilizing the Competitive Factor Knowledge in Enterprises (in German). Oldenbourg Verlag.

[37] M. Alavi and D.E. Leidner (2001). Review: Knowledge management and knowledge management systems: Conceptual foundations and research issues. MIS Quarterly, 107-136.
[38] G. Von Krogh, G. (2012) How Does Social Software Change Knowledge Management? Toward a Strategic Research Agenda. The Journal of Strategic Information Systems, 21, 154-164.

[39] P. M. Leonardi and J.W. Treem (2012). Knowledge management technology as a stage for strategic selfpresentation: Implications for knowledge sharing in organizations. Information and Organization, 22(1), 37-59.

[40] A.P. McAfee (2006). Enterprise 2.0: The Dawn of Emergent Collaboration. MIT Sloan Management Review, vol. 47, Nr. 3, pp. 21-28

[41] R. Vatrapu (2013). Understanding Social Business. In K. B. Akhilesh (Ed.), Emerging Dimensions of Technology Management (pp. 147-158 ). New Delhi: Springer Science+Business Media B.V.

[42] H. Geschka (1996). Creativity techniques in Germany. Creativity and innovation management, 5(2), 87-92.

[43] C. Brockmann, and N. Roztocki (2013), "Knowledge Economics Minitrack Introduction" In: 46th Hawaii Conference for System Sciences (HICSS), Wailea, USA, 2013.

[44] M. Homer, "Skills and competency management." (2001), Industrial and Commercial training 33, 2/2001, pp. 59-62.

[45] C. Brockmann, and N. Roztocki (2014), "The Evolution of Knowledge Economics through the Course of Time: An Analysis of the Hawaii International Conference on System Sciences (HICSS) Minitrack." In: 47th Hawaii International Conference on System Sciences, pp. 3471-3477. IEEE, 2014. 